\title{
Prenatal diagnosis and discrimination against the disabled
}

\author{
Lynn Gillam The Murdoch Institute, Royal Children's Hospital, Melbourne, Australia
}

\begin{abstract}
Two versions of the argument that prenatal diagnosis discriminates against the disabled are distinguished and analysed. Both are shown to be inadequate, but some valid concerns about the social effects of prenatal diagnosis are highlighted.
\end{abstract}

(Fournal of Medical Ethics 1999;25:163-171)

Keywords: Prenatal diagnosis; disability; discrimination; abortion

It is sometimes suggested, ${ }^{1}$ especially by disabilities rights advocates, that using prenatal diagnosis to detect genetic and other abnormalities in the fetus is a form of discrimination against the disabled. Alison Davis, a British disabilities rights advocate who describes herself as having severe spina bifida, claims that:

"In the specific case of women with disabilities, and the rights of handicapped people as a whole, it is becoming ever more obvious that the 'right' to abortion is denying us our very right to exist."

Similar claims are made by Helen Houghton and Christopher Newell, both Australian disability advocates:

"If prenatal diagnosis is used as a tool to eradicate as many disabilities as possible in society, then it does discriminate against people with disabilities: those who are already living with disabilities and those potential babies who may have lived very successfully with disabilities." 3

"The new genetic technologies, including prenatal diagnosis and termination, are inherently a technology of oppression and control, which serve to devalue the lives of people identified as having disabilities."4

As Allen Buchanan points out, there is no single disabilities rights position on prenatal diagnosis, and (as these quotes show) objections are expressed in different ways; however, the underlying common theme is that of discrimination against people with disabilities. ${ }^{5}$ Is this charge of discrimination justified?
I will focus specifically on prenatal diagnosis followed by termination of affected pregnancies ("selective abortion"), and not consider at all the possibility of therapeutic intervention after prenatal diagnosis, since this latter is recognised as raising somewhat different issues. ${ }^{6}$ I will identify two different interpretations of the discrimination charge against selective abortion: the "slippery slope" version and the conceptual version, ${ }^{7}$ and examine both. I will argue that both fail to establish that discrimination against people now living with disabilities is an inevitable part of selective abortion following prenatal diagnosis. But this does not mean that prenatal diagnosis is completely unproblematic. On the slippery slope version, discrimination is avoidable, but only provided that efforts are made to avoid it. On the conceptual version, prenatal diagnosis, though not discriminatory per se, involves a quality-of-life judgment about disability that people with disabilities may well find deeply offensive and personally hurtful.

Before discussing these two versions of the discrimination charge in detail, it will be helpful to clarify what I understand by disability and discrimination. Firstly, disability. I do not adopt a totally medical model of disability; in some senses and to some extent disability is socially constructed. That is, some physical and mental inabilities or losses of functioning are made into disabilities, or made more disabling, by the way society works both in terms of its physical set-up, and also in terms of the sorts of social interactions and ways of living that are expected of its members. However, I do not accept that disability is wholly socially constructed; there are some genetic and other conditions which would cause limitation and suffering no matter what the social setting. This is a view which I believe can be found in statements by at least some disability advocates. $^{8}$

With regard to discrimination, I do not want to adopt too rigid a definition, since doing so might artificially exclude some important considerations, or miss the point that disability advocates are making. I will consider discrimination both in 
the formal sense, as meaning something like denial of fair equality of opportunity, and also in the less formal, more everyday sense, as making judgments about people purely on the basis of their membership of a group which is seen by the dominant part of society as inferior in some way. ${ }^{9}$

\section{The slippery slope version of the discrimination charge}

The slippery slope version of the discrimination charge points to the negative outcomes that prenatal diagnosis and selective abortion will have (or are having) on people now living with disabilities. The basic idea is that use of prenatal diagnosis for this purpose will lead to or cause more injustice and greater discrimination against people with disabilities than currently exists. This is sometimes expressed in terms of perpetuating existing discrimination, but the underlying point is the same, that there is a causal connection between selective abortion and discrimination against people with disabilities. The exact nature of the effect-whether it is to increase the overall level of discrimination, or simply to keep it at existing levels when it would otherwise (ie in the absence of this technology) decrease-is not as important as the fact that the effect is a causal one, brought about by a causal mechanism of some sort. Slippery slope arguments are sometimes spurious because the feared result at the bottom of the slope is not actually morally bad, but that is not the case here. It does not need to be argued that increased discrimination against people with disabilities would be morally a bad thing. The question is whether such discrimination does indeed lie at the bottom of the slope. The focus of my attention will thus be on the mechanisms which might cause a slide to occur, and whether or not a discriminatory outcome is inevitable.

A number of potential causes of increased discrimination against people with disabilities can be identified. The one most frequently referred to in the literature is a decrease in the numbers of disabled people. Another potential cause is a change for the worse in social attitudes towards people with disabilities. Associated with this, there will be negative psychological effects on people with disabilities themselves. I will examine each of these postulated causes of increased discrimination in turn.

DECREASED NUMBERS OF PEOPLE WITH DISABILITIES The claim that prenatal diagnosis will cause a reduction in the number of people living with disabilities is based on the very clear evidence that in response to moderate to severe fetal abnormality, the vast majority of women choose to termina㱖 their pregnancy. For example, an analysis Wertz and Fletcher of previous studies off termination decisions after prenatal diagno shows that for a diagnosis of trisomy 13,18 or $2 \vec{d}$, Tay-Sachs, anencephaly, spina bifida or thalas aemia, between 73 and $100 \%$ of women chose termination (and most studies showed 100\%. The rate for sickle cell anaemia and sex chromgysome abnormality was somewhat lower, ranging from 38 to $79 \%$, but still significant. ${ }^{10}$ Further, these decisions are not limited to unusucal individual cases or special groups not represent

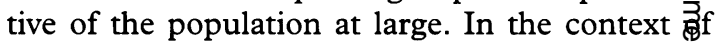
screening programmes, where prenatal testing offered to all women in a group on a voluntainy basis, there is a reduction in the number of birts of babies with the disability that has been screened for. One British study, for example, showed that $\stackrel{9}{\mathrm{~m}}$ a screening programme for Down's syndrom $\overrightarrow{\mathrm{e}}$, termination was chosen in $81 \%$ of cases whereqt was detected, and there was an overall reduction of $30 \%$ in births of babies with Down's syndrome. (The difference between the termination rate ara the reduction in the rate of Down's births wh caused by two factors - not all women chose to screened, and screening detected only about hadf of all cases of Down's syndrome actua货 present). ${ }^{11}$

However, two comments need to be made relation to this. Firstly, a mere reduction in nur bers of people with disabilities cannot in its iff cause (more) discrimination against such people, any more than an increase in numbers can bri about less discrimination. An extra step is needeg. This is usually supplied by the claim that smaller numbers will lead to disproportionately reducejd funding for disability services. ${ }^{12}$ But again, there 15 no straightforward connection here: Wertz ared Fletcher claim that it is "illogical" to argue straight from reduced numbers to reduced (per capit) funding. ${ }^{13}$ Although it may well be true thest governments are always seeking ways to cait expenditure, especially on health care, it is not obvious that a decline in numbers of people with disabilities would lead to an excessive cut in fun ing. There would not be any sudden drop in rates of disability which a government could seize on $\bar{\phi}$ justify funding cuts; only a gradual declinê. Perhaps this could even work in favour of peopte with disabilities: it is not inconceivable that numbers decline, funding will stay at the sanfe level, thus providing each individual with mo\%e than before. ${ }^{14}$ Increased support for people wif thalassaemia in a region of Greece, followingo widely utilised carrier screening programme and subsequent drop in numbers of babies born wi 
thalassaemia, is one actual example of this postulated outcome. ${ }^{15}$

A better explanation for a putative loss of funding stemming from reduced numbers of people with disabilities is that the smaller numbers will result in a smaller social presence. This means less ability to organise effectively, to win public support, to lobby governments to maintain and improve services and so on. In short, if the decline in numbers is great enough, a critical mass might be loss, and this could result in loss of services which provide people with disabilities with fair equality of opportunity to participate in society and to enjoy its benefits.

However, the second comment which needs to be made on the reduction of numbers argument completely undercuts this point. For quite simply, there is no good reason to think that increased use of prenatal diagnosis and selective abortion will result in a significantly smaller number of people living with disabilities. There are two explanations for this. Firstly, most disabilities do not arise from genetic or other abnormality which is detectable prenatally. Rather, they arise from injury or illness later on, ranging from prematurity and injury at birth, to road trauma (where a decrease in road deaths is frequently accompanied by an increase in severely and permanently disabled survivors) and disease of all sorts. ${ }^{13}$ Secondly, prenatal diagnosis, even when accompanied by high rates of termination for affected pregnancies, will not necessarily reduce the number of babies born with genetic and congenital abnormalities. Take the case of Down's syndrome to see how this is so. One of the major risk factors for Down's syndrome is advanced maternal age. After the age of 35, the risk increases significantly for each extra year of age. The current social trend is for women to delay having children. In Australia, for example, the proportion of births to women over 35 increased from $7 \%$ to $9.5 \%$ in the years 1982 to 1988 ; and by 1996 , women over 35 comprised $15 \%$ of the total number of women giving birth in that year. ${ }^{16}$ This trend means that the number of fetuses with Down's syndrome is actually rising, even though the overall birth rate remains steady. So even if prenatal diagnosis decreases the rate of Down's births in a given population to a level $30 \%$ less than it would otherwise have been, the actual number of Down's births may well stay the same, since the number of affected pregnancies is increasing. ${ }^{17}$ Prenatal diagnosis may do no more than contain what would otherwise be a significant increase in the number of babies born with Down's syndrome.

In summary, the idea that prenatal diagnosis will cause a noticeable fall in the number of peo- ple living with disabilities is not supported by the evidence. Thus the feared loss of funding, and subsequent loss of services which promote equality of opportunity for people with disabilities, will not occur by this means. Insofar as the slippery slope argument depends on decrease in numbers, it does not work. However, other factors may cause increased discrimination, even if the number of people with disabilities stays the same, so the slippery slope argument is not yet invalidated.

\section{HOSTILE SOCIAL ATTITUDES}

The extent of discrimination against people with disabilities in many Western societies has decreased significantly over the past 20 to 30 years. ${ }^{18}$ Largely through the efforts of disability activists, people with disabilities have won increased recognition of their right to participate in society, and have equal access to the goods it offers, such as education, employment, sporting and leisure activities, personal relationships and parenthood. This is reflected both in legislation prohibiting discrimination on the grounds of disability (and other characteristics, such as race and religion), and in provision of government services and programmes to assist people with disabilities to take up opportunities for employment, education and so on. It is also reflected in increased social acceptance of people with disabilities participating in mainstream society. However, these gains are not set in concrete, and could be overturned if there arises in a society some impetus to view disability more negatively. This is one major effect that disability advocates fear from prenatal diagnosis.

On this view, once prenatal diagnosis and selective abortion become routine, social attitudes to disability may change markedly. Before the advent of prenatal diagnosis, the birth of a child with a disability was unpredictable and unavoidable. But with prenatal diagnosis, it is no longer so. The birth of a child with a disability now increasingly becomes a matter of conscious choice, since the option to detect and terminate an affected pregnancy is available. In this environment, parents who do not choose to terminate, or who do not even use prenatal diagnosis, may come to be seen as acting irresponsibly or recklessly. ${ }^{19}$ People with disabilities (especially ones that are recognisably genetic or prenatal in origin, such as Down's syndrome and spina bifida) may come to be seen as accidents that should never have happened. Such a change of attitude, especially if widespread, could indeed lead to increased discrimination against people with disabilities. This could take the form of increasing stigmatisa- 
tion of people with disabilities as a burden upon society, and their increasing social marginalisation. Further, if responsibility for having disabled children is attributed to parents, this may prompt governments to withdraw funding and services, on the rationale that since the parents have recklessly brought disabled children into existence, when they could have avoided it, they must pay for the consequences. On this scenario, opportunities for people with disabilities will inevitably be reduced, even if governments maintain a legislative commitment to formal non-discrimination. Individual parents, even if they happen to be wealthy (as many will not be), would be unable to create the structures and programmes, such as mainstream schooling and affirmative action, which provide disabled people with fair equality of opportunity.

A further result of the development of hostile social attitudes towards disability may be the demoralisation of people now living with disabilities. The negative views of disability just described could send a message to people now living with disabilities that others regard their lives as unhappy, unproductive and unwanted. Adrienne Asch claims that this message is already being sent:

“... prenatal diagnosis and selective termination communicate that disability is so terrible that it warrants not being alive... . As a society, do we wish to send the message to all such people now living that there should be no more of your kind in the future?"20

As is clear from Asch's comments, this sort of message can be received by people with disabilities even when those who provide or use prenatal diagnosis neither hold such views themselves nor intend to communicate them. So this objection cannot be dismissed just by re-stating the "official view" 21 that the purpose of prenatal diagnosis is simply to provide choice for parents, and implies no negative judgment about disability. For in spite of this, it is apparent that the reality of termination as the standard response to the detection of fetal abnormality is readily interpreted by people with disabilities as an indication that the medical profession, and society at large, think it would be better if babies with disabilities were never born. Whilst this opinion is not discriminatory against people with disabilities as such (as I will attempt to show in the next section), it is certainly offensive and demoralising to at least some disabled people. If disabled people come to feel that the rest of society thinks that they should not exist, they may find it much harder to lobby and advocate on their own behalf to retain and improve the services and opportunities that they currently have. After all, this sort of active requires considerable determination, optimis and belief in oneself and the justice of one's cause - all of which are likely to be undermined implicit messages that one should not even exist.

The possibility of these sorts of discriminatowy outcomes, cannot, I think, be denied. But whether they are an inevitable accompaniment of prenal diagnosis, or conversely, can be avoided in some way, is another matter. Some writers in the field, both disability advocates and others, believe that the nexus can be broken, and that the technology can be used without the negative social effects. Deborah Kaplan, a disability advocate, takes t view that:

"It should be possible to talk about prenafal screening without assuming that disability $\overrightarrow{\text { Fु }}$ tragic, painful and burdensome at all times for oll people." 22

In theory, this must be correct - it must be posable to attach disvalue to pain, suffering amd limitation, without thinking that everything thgt society labels as a "disability" is always $\mathscr{S}^{\mathrm{n}}$ unremitting tragedy. Likewise, it must be possibfe to draw a distinction between the disvalue ofa disability per se, and the value of the person wh the disability - we can think of disability as bod without being committed to thinking of peope with disabilities as bad. ${ }^{23}$

\section{An open question}

But if negative attitudes towards people with disabilities are not to be increased or reinforced Ey prenatal diagnosis, it will be necessary to commnicate these more positive ideas persuasively to the population at large. In my judgment, it remains in open question whether this can successfully Be done. Clearly it would require a significagt conscious effort on the part of government and the providers of prenatal screening services cannot just hope that it will happen spontaneously. There would need to be programmes aimed both at influencing public attitudes towards disability, and at ensuring that services for peophe with disabilities were maintained. This is rectnised by at least some diagnostic serve providers ${ }^{24}$ and some significant efforts are bei made. ${ }^{25}$ These are perhaps better known by the users of genetics services than by the general puiflic, but do provide a good model. However, the model would need to be widely followed in orfer to have a good chance of achieving the desired effect. So whilst it is in theory correct to say that prenatal diagnosis and selective abortion will not inevitably lead to increased intolerance of peo with disabilities, there are dangers of negatuie 
social outcomes, which need to be recognised and combated.

The slippery slope argument, then, does not provide a cut-and-dried objection to prenatal diagnosis and selective abortion. First, it does not show that increased discrimination against people with disabilities is an unavoidable outcome. It does sound some warning bells, and emphasise the importance of taking seriously the possible social effects of what appear at first glance to be private reproductive decisions; but it does not show that bad outcomes for people with disabilities are inevitable. Secondly, it should be noted that even an actual increase in discrimination against people with disabilities caused by prenatal diagnosis would not necessarily prove that it is morally wrong for a society to use prenatal diagnosis. This is because the moral disadvantages of discrimination would have to be weighed against the advantages of using prenatal diagnosis, which include increased individual reproductive autonomy and increased overall wellbeing in the future population..$^{26}$ Exactly where the balance would lie here would need to be debated-but it cannot simply be assumed that nothing could justify even a slight rise in any form of discrimination against people with disabilities.

\section{The conceptual version of the discrimination argument}

The conceptual version of the discrimination argument does not depend on any empirical claims about the effects of prenatal diagnosis and selective abortion. Rather, it focuses on the inherent nature of selective abortion decisions, and the values underlying them. On the conceptual version, selective abortion in itself constitutes or necessarily implies discrimination against people with disabilities, regardless of any additional discriminatory side effects it may have. This version of the argument is much more complex than the slippery slope version, and I cannot deal with all its nuances here. I will focus on just one way of approaching this argument, which is to look at the moral values which underpin the decision to abort an affected fetus, and to ask whether these values are themselves discriminatory to people now living with disabilities.

\section{JUSTIFICATIONS FOR SELECTIVE ABORTION}

In terms of ethical theory, abortion is generally seen to be justified where low moral status is attributed to the fetus. Within this context, three distinct justifications for aborting a fetus found to have an abnormality can be offered. These are: (1) the best interests of the child-to-be, (2) a comparison with a future possible non-disabled child, and (3) the best interests of the woman (mother-to-be). The first two of these involve a direct assessment of the quality of life of the disabled child-to-be; the third does not, although it does make predictions about the effect on the mother of having a child with a disability, which might indirectly imply an assessment of the quality of life of the disabled child. I believe that it is the quality of life judgment about the disabled child-to-be that is the basis for the view that selective abortion is inherently discriminatory against people with disabilities. Accordingly, I will direct my attention to the first two forms of justification, where quality of life is an explicit and integral feature.

In order to keep the discussion concise and focused, I will not consider at all here the third form of justification, which relates to the impact on the mother-to-be. Nor will I consider the very important question of the extent to which these ways of justifying selective abortion are morally sound. As it happens, I take the view that the first two justifications are quite problematic, resting in turn on unrealistic assessments of the quality of life of most people with disabilities, and on implausible views about the nature of morality. It is the third justification (the one which does not involve any direct quality of life assessment in relation to disability) that I regard as the most defensible, because it refers to the same factors (namely the autonomy and wellbeing of the pregnant woman) that are regarded as justifying abortion in other contexts. However, this form of justification of selective abortion is not often advanced in the literature, and could fairly be regarded as non-standard. For this reason, I will not use it as the basis for my discussion. I will set it aside now (though it is worth defending on another occasion) to deal with the quality-of-life-based justifications of selective abortion, since these are by far the most common, and, in my view, the most likely basis for the discrimination objection.

In the following sections, I will show how assessments of the quality of life of a person with a disability are used to make a moral judgment in favour of selective abortion. Then I will argue that these unfavourable quality-of-life assessments cannot, strictly speaking, be regarded as discriminatory towards people with disabilities. This is because they are not applied to people now living, but to fetuses, to ground a decision about what may be done to a fetus. This is the crucial point, because on the understanding of abortion considered here, fetuses are not persons, and moral decisions about fetuses cannot logically be extended to persons. ${ }^{27}$ 
Before going into a detailed account of the role of quality-of-life assessments in justifying selective abortion, it is worthwhile to note that the theoretical justifications just listed do appear broadly to reflect the actual considerations taken into account by women contemplating abortion after prenatal diagnosis. Wertz and Fletcher report that parents abort for a complex mix of reasons, which the parents themselves sum up as "the kind of life the child would have" or "what our life would be like". ${ }^{28}$ They cite various studies and case reports where women who have made the difficult and stressful decision to terminate their pregnancy have felt that having prenatal diagnosis gave them the freedom "to go on with their lives, to continue their careers, and to have healthy children". ${ }^{29}$ In all of this can be seen concern about the child who would be born, future children who might be born, and the woman (including her partner and already existing children).

\section{JUSTIFICATIONS OF SELECTIVE ABORTION BASED ON}

THE QUALITY OF LIFE OF THE CHILD-TO-BE

When abortion in general is seen as morally legitimate, the usual reason is the low moral status attributed to the fetus. When quality-of-life considerations come in, they almost always do so against this background assumption. It is important to keep in mind the moral status attributed to the fetus when it comes to the question of discrimination against people with disabilities.

In relation to the special circumstance of fetal abnormality, considerations of the quality of life of the child-to-be can be seen to justify selective abortion in two ways: (i) in relation to the best interests of the child-to-be, taking into account the effects of the disability, and (ii) in comparison with the quality of life of a possible future non-disabled child. Both of these approaches involve making an explicit assessment of how life with a certain kind of disability will be for a person, from that person's point of view. Factors which would come into such an assessment include life expectancy, likely functional abilities and disabilities, pain and suffering, hospitalisation, prospects for social interaction, independent living, education and so on.

\section{The best interests of the child-to-be}

The first way of using the quality-of-life assessment is in relation to the best interests of the child-to-be. Quality of life may seem to be so bad, the prospects so bleak, that life would not be in the best interests of the child-to-be. Or, put more bluntly, as the disability advocates quoted earlier do, the child would be "better off dead than disa- bled". The moral argument for selective abortion then goes like this: it is in the best interests of the child-to-be never to be born, and, other things being equal, we ought to promote people's begt interests, so abortion is the right thing to do. The is a familiar, well recognised argument in favour $f$ selective abortion..$^{30}$ Note that this argument is theory applicable whether the fetus is regarded क्gs having full moral status (equivalent to a persona), or low moral status. That is, abortion could theoretically be seen as justified in cases where future quality of life would be so poor as to be worse thath death, even if the fetus was held to be a person and abortion held to be wrong for every other reaso Selective abortion in this context would be a prionatal form of non-voluntary euthanasia (which 行, of course, itself, controversial). However, in praetice, the argument from the best interests of the child-to-be occurs in conjunction with the postion that the fetus does not have full moral status, and thus that abortion is justified for a number $\frac{\text { af }}{4}$ reasons, of which poor future quality of life is justit one.

\section{Comparison with the quality of life of a non-disabled child}

The second way of using the quality-of-life assessment is to compare the life of this disabled chilg to-be with that of a future possible non-disablêd child - the child that woman could have if she d not have this child. On this approach, the qualipy of life of the disabled child-to-be is not judged be so terrible that death would be preferable - it is simply judged to be lower than that of a child who has no disability. The use of this quality-of-1iffe comparison as a justification for selective aborti@n is perhaps less familiar, although it too is well established in the literature. The basic line $\mathrm{f}$ thought is that if there is a choice between having a disabled child now and having a non-disable child later, the morally right choice is to have the non-disabled child, since that child will have better life. When applied to abortion, rather thå a choice about when to start a pregnancy, this life of thinking justifies aborting for fetal abnormaltioy - provided that two assumptions are made. ए

The first assumption needed is that the fetas must be regarded as having low moral status, థ్థ that it is "replaceable", to use a term from Jonathan Glover, one of the main proponents $\mathrm{Bf}_{\mathrm{f}}$ this style of justification for selective abortion This means that there is nothing morally specall about an individual fetus, and thus no moral reason to continue this pregnancy, rather than ternnate it and start another one at a later date. TRe second assumption needed is a broadly utilitarian view of morality, according to which the basic 
moral obligation is to maximise quality of life (or "worthwhile lives", as Glover puts it). ${ }^{32}$ When these two assumptions are combined with the assessment that the quality of life of a disabled child is almost always lower than that of a non-disabled child, this produces the conclusion that selective abortion is justified. According to Glover: "If aborting the abnormal fetus can be followed by having another, normal one, then it will be wrong not to do this." ${ }^{32}$ (Note that on Glover's formulation, selective abortion is actually morally obligatory, rather than simply morally acceptable, but he resists the idea that a pregnant woman who does not want an abortion should be forced to have one, on the basis of the bad consequences of such coercion.)

\section{ARE QUALITY-OF-LIFE CONSIDERATIONS \\ DISCRIMINATORY?}

The important question for our purposes here is not whether these two modes of justifying selective abortion are sound and well supported (that is an issue for a separate occasion) but whether they are discriminatory to the disabled. I will argue that if the fetus is understood to have low moral status, as it is in both versions of the quality-of-life justifications discussed above, and can thus legitimately be killed in circumstances which would not justify the killing of a person, then prenatal diagnosis and selective abortion are not inherently discriminatory to the disabled. A person with a disability might very reasonably find the quality-of-life assessments involved deeply offensive - but feeling offended is not equivalent to being discriminated against.

My argument is based on the distinction between a quality-of-life assessment in itself, and the moral conclusion that the assessment is taken to warrant. A quality-of-life assessment does not constitute a moral judgment - by itself, it is not a judgment about the moral status of persons, their comparative moral worth, the obligations they are owed or the rights they have. As such, it cannot in itself be discriminatory. Of course, a quality-of-life assessment may be used to ground a moral judgment about how a person ought to be treated or regarded by others, and that judgment could be discriminatory. It all depends on the moral premise which is added to the quality-of-life assessment. The most common moral conclusion drawn from the observation that someone has a low quality of life is that something must be done to help: this is reached by adding the moral premise that we have an obligation to assist others. This is the rationale for medical treatment: when a doctor sees a person suffering pain and dysfunction from, say, a broken leg, the response is to relieve the pain and restore the function. So assessing that a person's quality of life is low does not automatically lead to the conclusion that the person should be ignored, ostracised or mistreated: indeed usually quite the contrary.

To clarify this point about the distinction between morally neutral quality-of-life assessment and (potentially discriminatory) moral judgments, consider an example removed from the controversial area of disability. Take a person in the terminal stages of cancer. Someone looking on might judge that this person has a very low quality of life - she might have intractable pain, for example, and very limited ability to move around and interact with others. This quality-of-life judgment by itself, however, does not license discriminatory treatment of this person. It does not imply that she has lower moral status than other persons, or less rights. It does not imply that it is morally acceptable to withdraw care and attention from her, lie to her about her situation, steal her possessions, or kill her against her wishes. All these would indeed be morally wrong, and, if done on the basis that she has a low quality of life and thus has less moral rights than the rest of us, would be discriminatory. But the important point is that the quality-of-life assessment by itself does not automatically lead to these discriminatory conclusions.

\section{Morally different entities}

For prenatal diagnosis and selective abortion, then, the vital issue is not whether a quality-of-life assessment about life with a disability is made, but what this assessment is taken to license. So what does it license in prenatal diagnosis? It licenses the conclusion that termination of pregnancy is justified - that is, that killing the fetus is morally justified. Now if the fetus were regarded as having a high moral status, equivalent to a person, then by logical extension, low quality of life would also justify the killing of a child or adult with a disability. This would be a denial of the right to life of disabled persons, and would indeed be highly discriminatory. But remember that the two qualityof-life justifications for selective abortion both assume that the fetus does not have high moral status - the fetus is not equivalent to a person, and that is what makes abortion morally justified. Now the low moral status of the fetus drives a moral wedge between fetuses with abnormalities and people with disabilities - they are morally different entities, and conclusions about one cannot simply be transferred to the other. So the use of qualityof-life assessments to justify killing fetuses with abnormalities in no way discriminates against people with disabilities, since it does not, strictly speaking, have any moral implications for them. 
For people with disabilities, however, this is not the end of the story. Selective abortion of fetuses with abnormalities may not have moral implications for them, but it can have personal implications. Assessments of the expected quality of life of a disabled child-to-be are inevitably very closely connected with assessments of the quality of life of people now living with disabilities. (If prospective parents and their medical advisers do not get their information about life with a disability from looking at the lives of disabled people, then where do they get it from?) For people with disabilities, to have someone else look at their lives from the outside, and make judgments about how fulfilling and how happy they are, must be deeply offensive partly because it is so presumptuous to make these sorts of assessments about others' lives, but more especially because the outsiders' assessment is very often so much more negative than their own assessment, and so betrays a woeful lack of understanding of what their lives are really like. The worst form of this occurs in the "best interests of the child-to-be" justification of selective abortion, where the assessment is that this disability is so bad that a child-to-be would be better off dead than disabled in this way. The assessment is not so damning in the "future possible child" version, where it is judged only that life with this disability would be worse than life with no disability - not that it would be worse than death. But regardless of philosophers' justifications, or the actual reasoning of prospective parents who choose abortion, it is clear that many people with disabilities understand selective abortion in the "better dead than disabled" sense. And quite reasonably, they find it personally offensive and distressing.

However, as I pointed about above, the fact that a practice is offensive to some section of the community does not make it morally wrong to engage in it, or cause it to be discriminatory to the minority. This question of offensiveness has been widely debated $^{33}$ in connection with a range of different issues (perhaps most famously the decriminalisation of homosexuality in Great Britain, in the so-called Hart-Devlin debate). The liberal position, advanced for example by HLA Hart, ${ }^{34}$ that offensiveness to others is not in itself grounds for moral wrongness or legal sanction, is in my view compelling. This does not mean that offence or psychological distress caused to people with disabilities does not matter. It certainly does, and there is good moral reason to try to avoid or at least minimise such effects. But the fact that selective abortion is offensive to many people with disabilities does not in itself make selective abortion discriminatory to those who are offende by it.

\section{Conclusion}

The discrimination objection to prenatal diagno sis and selective abortion, in both its slippery slope and conceptual forms, does not provide a conclysive argument against prenatal diagnosis anfd selective abortion. Discrimination against peop $\overrightarrow{P e}$ with disabilities is neither an inevitable result $\overrightarrow{\overrightarrow{f f}}$ prenatal diagnosis, nor is it a necessary concept商 part of it. However, the objection does make cle $\overline{\bar{g}} \mathrm{r}$ the potential for significant negative effects $\mathbb{R}_{\mathrm{R}}$ people with disabilities, and it would be moraHy wrong to dismiss these as trivial or irrelevant. If prenatal diagnosis is to proceed in an ethicalify acceptable way, these negative effects must ge recognised, acknowledged and countered as far possible.

Lynn Gillam is Research Fellow in the Ethics Unit, The Murdoch Institute, Royal Children's Hospital, Melbourne and Lecturer, Centre for th Study of Health and Society, University of Melbourne, Australia

\section{References and notes}

1 For example, see Holtug N. Against human gene therapy. Cambridge Quarterly of Healthcare Ethics 1997;6:159.

2 Davis A. Women with disabilities: abortion and liberation. Disisability, Handicap and Society 1987;2.3:276.

3 Houghton $H$. Does prenatal diagnosis discriminate against the disabled? In McKie J, ed. Ethical issues in prenatal diagnosis ard termination of pregnancy Melbourne: Centre for Human Bioetics, 1994:97-102: 98.

4 Newell C. Critical reflections on disability difference 2 d genetic testing. Unpublished paper presented to the Gen ic Testing, Ethics and Public Health seminar of the Public Health Association of Australia New South Wales Branch at Rofal North Shore Hospital, Sydney, 1997 Aug 15.

5 Buchanan A. Choosing who will be disabled: genetic intervtion and the morality of inclusion. Social Philosophy and Po Isy 1996;13.2:18-45: $n 7,21$.

6 See for example reference 5:30-1.

7 Buchanan also identifies two versions: see reference $5: 21,28$. He calls these the "loss of support" and the "expressivist" argtments. However, these categories are not the same as mine: ns "loss of support" is narrower than my slippery slope, since. postulates only one cause, namely reduction in numbers, 迅 his "expressivist" is wider than my conceptual, including considerations about outcomes which I think properly belofg in the slippery slope category.

8 For example, Asch A. Reproductive technology and disabilin. In Cohen C, Taub N, eds. Reproductive laws for the 1990s. Clifton, NJ: Humana Press, 1988: 69-123, at 73

9 Campbell T, Heginbotham C. Mental illness: prejudice, discri nation and the law Aldershot: Dartmouth Publishing Compa蜘, 1991:3-29.

10 Wertz DC, Fletcher JC. Feminist criticism of pren\&al diagnosis: a response. Clinical Obstetrics and Gynaecology 1993 ; 36.3:541-547, at 555 .

11 Wald NJ, Kennard A, Densem JW, Cuckle HS, Chard T, Buther L. Ante-natal maternal serum screening for Down's syndronge: results of a demonstration project. British Medical foukal 1992;305:391. 
12 Reduction in funding for services is, of course, not the only measure of increased discrimination. It may not even be the best one. However, the literature focuses almost entirely on funding, perhaps because it is so easily calculated and quantified, in comparison with other methods of measurement. 13 See reference 10: 551 .

14 This possibility is canvassed by Munthe $\mathrm{C}$. The moral roots of prenatal diagnosis. Goteburg: Centre for Research Ethics, The Royal Society of Arts and Sciences in Goteburg, 1996:63.

15 See reference 5:22.

16 Figures from the Australian Bureau of Statistics, as reported by Chamberlain P. Women wait longer for babies as fertility falls. The Age 1995 Sept 23:A3.

17 Borthwick C. The prevention of disablement. In McKie J, ed. Ethical issues in prenatal diagnosis and the termination of pregnancy Melbourne: Centre for Human Bioethics, 1994:103-114, at 109.

18 See reference 8:75.

19 Wertz and Fletcher make a similar point - see reference 10:552.

20 Asch A. Can aborting "imperfect" children be immoral? In Arras JD and Rhoden NK, eds. Ethical issues in modern medicine [3rd ed]. Mountain View, Calif: Mayfield Publishing Co, 1989: 319.

21 See reference 14: ch 2.

22 Kaplan D. Disability rights perspectives on reproductive technologies and public policy. See reference 8:241-247, at 246 .

23 This distinction is emphasised by Buchanan. See reference $5: 32$.

24 See for example Williamson B. Healthy genes in a healthy body. World Health 1998;2:28.

25 For example, the Victorian Clinical Genetics Service (VCGS) in Australia, having been actively involved with a range of support groups for people with genetic disorders, has recently employed a social worker with the specific job of setting up an umbrella organisation for all these support groups, called the Victorian Genetics Support Network. The aim of this organis- ation is to provide resources for the support group and facilitate consumer feedback to the VCGS. (See the 1997 Annual Report of The Murdoch Institute. Parkville, Melbourne: The Murdoch Institute, 1997:75.)

26 It would be open to disability advocates at this point to argue that these are not in fact moral benefits at all-that morally acceptable reproductive choices do not include the choice to abort for fetal abnormality, and that the future population would be just as well off, perhaps even better off, if it included people with disabilities. These claims are worthy of debate, but I cannot address them here.

27 If fetal status is understood differently, then of course this point will not apply. In particular, the situation might be different for the later fetus rather than the early fetus. Some abortions for fetal reasons are carried out quite late, due to the stage of pregnancy at which the diagnostic tests can be performed. Those who believe that the fetus at this stage has acquired full moral status would presumably be opposed to such abortions; if they were to regard them as permissible, then there would be implications for people now living with disabilities, since in both cases a person would be involved. But to permit abortion for fetal abnormality when the fetus is regarded as a person seems to me to be an unusual and difficult view to hold.

28 See reference 10:554.

29 See reference 10:546.

30 See for example Glover J. Causing death and saving lives London: Penguin Books, 1990:146-7; and reference 13:47-8.

31 See reference 30:140.

32 See reference 30:146.

33 For example, see Feinberg J. The moral limits of the criminal law: Vol.3 Offense to others. New York: Oxford University Press, 1985; and Dworkin RM, ed. The philosophy of law. Oxford: Oxford University Press, 1977.

34 Hart HLA. Law, liberty and morality. Oxford: Clarendon Press, 1970. 